\title{
Respiratory medicine at McMaster University, Hamilton, Ontario: 1968 to 2013
}

\author{
Norman L Jones MD FRCP FRCPC, Paul M O'Byrne MB FRCPC FRSC
}

\begin{abstract}
NL Jones, PM O’Byrne. Respiratory medicine at McMaster University, Hamilton, Ontario: 1968 to 2013. Can Respir J 2014;21(6):325.
\end{abstract}

The medical school at McMaster University (Hamilton, Ontario) was conceived in 1965, and admitted the first class in 1969. John Evans became the founding Dean and he invited EJ Moran Campbell to be the first Chairman of the Department of Medicine. Moran Campbell, already a world figure in respiratory medicine and physiology, arrived at McMaster in September 1968, and he invited Norman Jones to be Coordinator of the Respiratory Programme.

At that time, Hamilton had a population of 300,000 , with two fulltime respirologists, Robert Cornett at the Hamilton General Hospital and Michael Newhouse at St Joseph's Hospital. From the clinical perspective, the aim of the Respiratory Programme was to develop a network approach to clinical problems among the five hospitals in the Hamilton region, with St Joseph's Hospital serving as a regional referral centre, and each hospital developing its own focus: intensive care and burns units at the Hamilton General Hospital; cancer at the Henderson (later Juravinski) Hospital; tuberculosis and rehabilitation at the Chedoke Hospital; pediatrics and neonatal intensive care at the McMaster University Medical Centre; and community care at the Joseph Brant Hospital in Burlington. The network provided an ideal base for a specialty residency program. There was also the need to establish viable research.

These objectives were achieved through collaboration, support of hospital administration, and recruitment of clinicians and faculty, mainly from our own trainees and research fellows. By the mid-1970s, the respiratory group numbered more than 25; outpatient clinic visits and research had grown beyond our initial expectations. The international impact of the group became reflected in the clinical and basic research endeavours.

ASTHMA: Freddy Hargreave and Jerry Dolovich established methods to measure airway responsiveness to histamine and methacholine. Allergen inhalation was shown to increase airway responsiveness for several weeks, and the late response was shown to be an immunoglobulin E-mediated phenomenon. Paul O'Byrne and Gail Gauvreau showed that the prolonged allergen-induced responses were due to eosinophilic and basophilic airway inflammation and, with Judah Denburg, revealed upregulation of eosinophil/basophil progenitor production in bone marrow and airways. The Firestone Institute became the centre of studies identifying the inflammatory phenotype of patients with difficult-to-control asthma. Freddy Hargreave and others developed methods for sputum induction to identify persisting eosinophilic airway inflammation and documented its presence in the absence of asthma, and in patients with persistent cough. Parameswaran Nair has applied these techniques to the management of asthma in routine clinical practice. The Asthma Quality of Life Questionnaire and the Asthma Control Tests were developed by Liz Juniper and Gordon Guyatt. The first Canadian evidence-based clinical guidelines for asthma management in 1989 were coordinated by Freddy Hargreave, Jerry Dolovich and Michael Newhouse.
DISTRIBUTION OF INHALED PARTICLES: Michael Newhouse and Myrna Dolovich used inhaled radiolabelled aerosols to study the distribution of inhaled particles and their clearance in normal subjects, smokers and patients with chronic obstructive pulmonary disease. They developed the aerochamber, and were the first to radiolabel therapeutic aerosols to distinguish the effects of peripheral versus central deposition. Particle deposition and clearance were shown to be impaired in ciliary dyskinesia and cystic fibrosis.

DYSPNEA: Moran Campbell and Kieran Killian measured psychophysical estimates of the sense of effort in breathing in studies of loaded breathing and exercise to show that dyspnea increased as a power function of both duration and intensity of respiratory muscle contraction, and in relation to reductions in respiratory muscle strength. These principles also applied to dyspnea in cardiorespiratory disorders.

EXERCISE CAPACITY: Norman Jones and Moran Campbell developed a system for noninvasive cardiopulmonary exercise testing using an incremental exercise test, and more complex studies with measurement of mixed venous $\mathrm{PCO}_{2}$ by rebreathing. The 6 min walk test was validated by Gordon Guyatt. Kieran Killian and Norman Jones introduced routine muscle strength measurements in clinical testing and symptom assessment in exercise testing. Muscle strength training improved exercise capacity in older subjects and patients with chronic obstructive pulmonary disease.

METABOLISM AND ACID-BASE CONTROL IN EXERCISE: After showing that imposed acidosis reduced, and alkalosis improved performance, Norman Jones, John Sutton and George Heigenhauser investigated the interactions between acid-base status and metabolism in exercise.

HIGH-ALTITUDE MEDICINE: John Sutton and Peter Powles participated in high-altitude research on Mount Logan (Yukon), demonstrating sleep hypoxemia in acute mountain sickness and its reversal by acetazolamide, and participated in Operation Everest II.

EPIDEMIOLOGY: David Pengelly and Tony Kerrigan followed children living in areas with differing air quality to show that lung development was adversely affected by pollution and maternal smoking. Malcolm Sears and Neil Johnstone showed that the 'return to school' asthma exacerbation epidemic was due mainly to rhinoviruses. David Muir investigated the effects of silica exposure in hard-rock miners, and mortality in the nickel industry.

SUMMARY: The Respirology Division has grown to more than 50 physicians and $\mathrm{PhD}$ scientists, currently provides the busiest outpatient clinic in Hamilton, and has successful training and research programs.

The full-length article can be viewed on the Journal's website at www.pulsus.com 


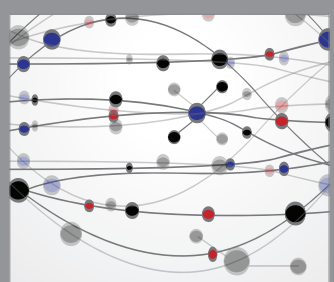

The Scientific World Journal
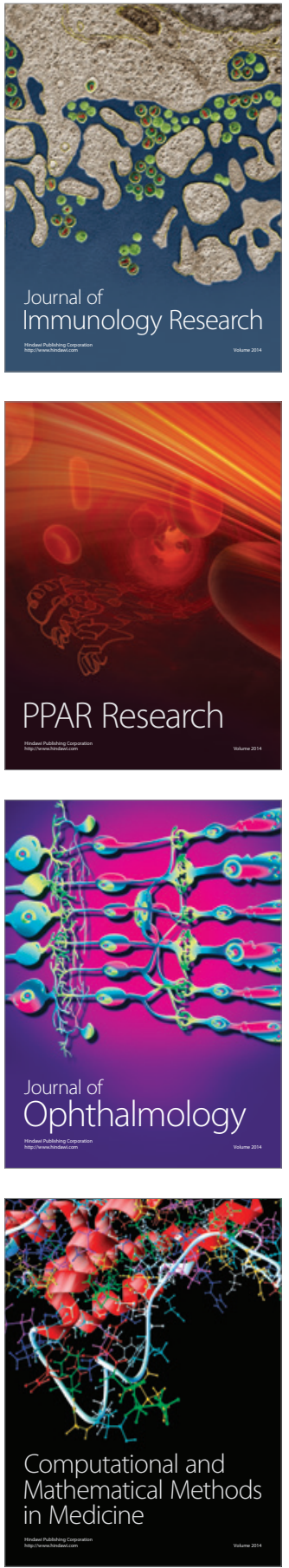

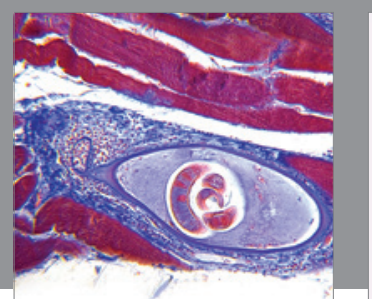

Gastroenterology Research and Practice

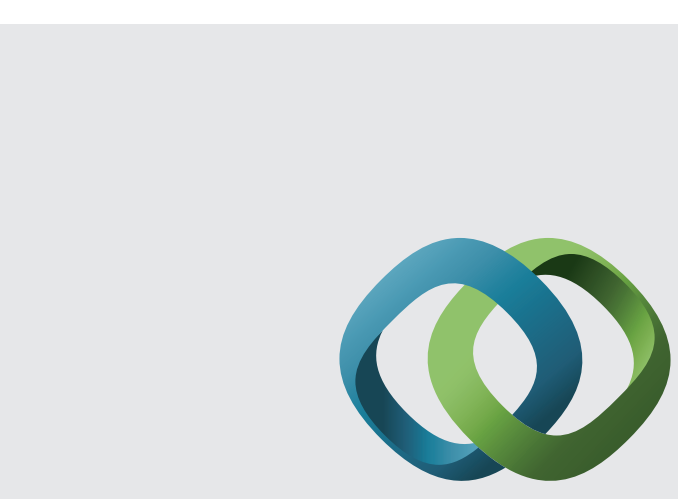

\section{Hindawi}

Submit your manuscripts at

http://www.hindawi.com
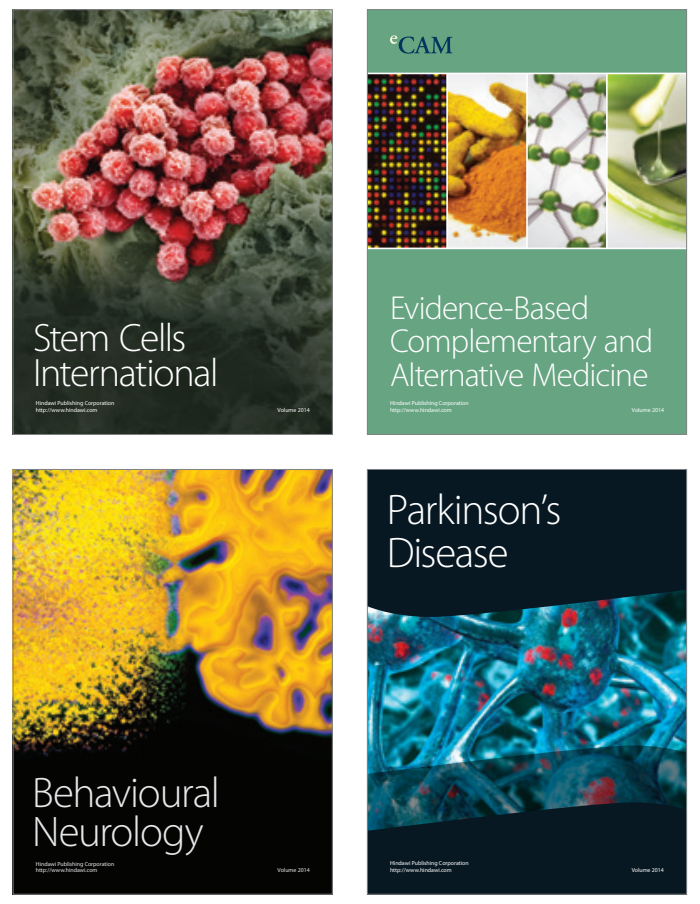
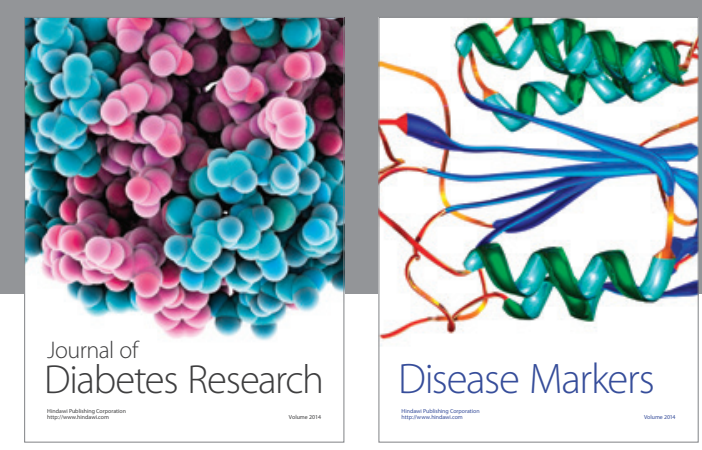

Disease Markers
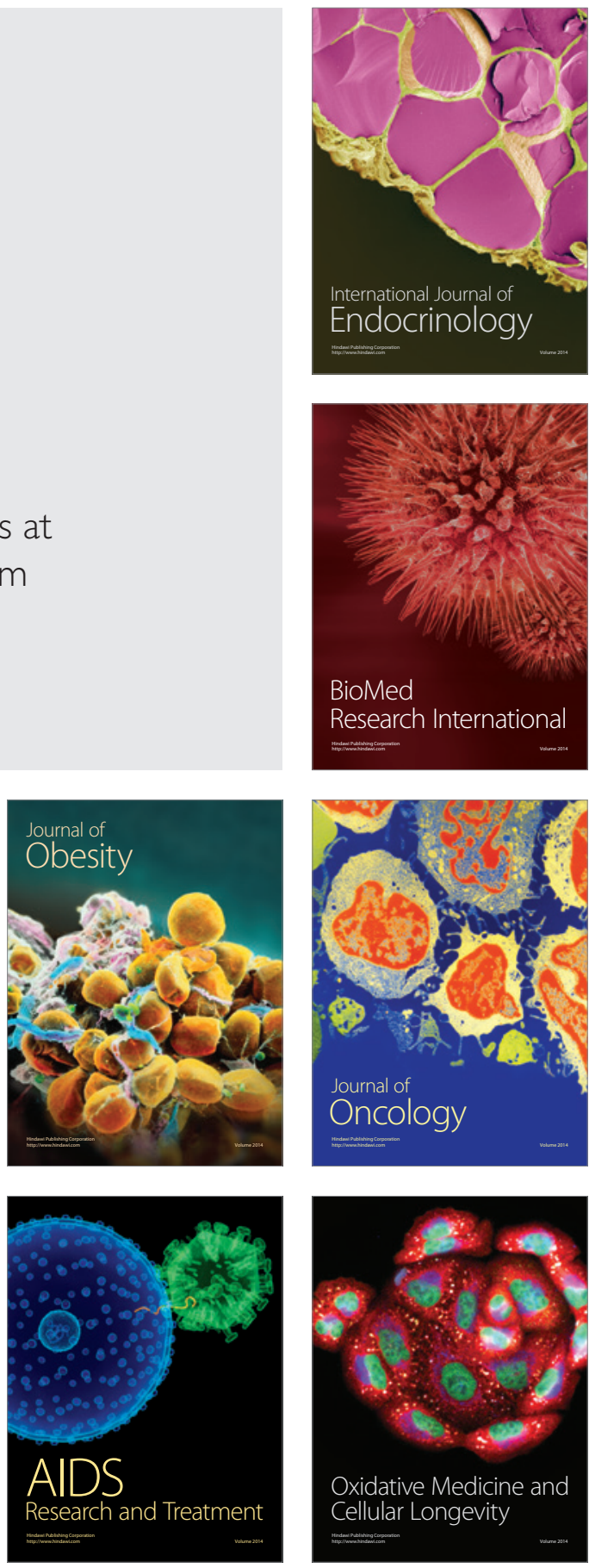